$$
\begin{gathered}
E 66-m-91517 \\
\text { Comb- }-720104--33 \\
\text { Log Nr. } 027
\end{gathered}
$$

SAFETY QUESTIONS RELEVANT TO NUCLEAR THERMAL, PROPULSION

David Buden

Idaho National Engineering Laboratory

P.O. Box 1625

Idaho Falls, ID 83415-1550

(208) 525-5626
EGG-M--91517

DE92 011152

MAR 261992

CAMERA READY MANUSCRIPT prepared for:

Ninth symposium

on Space Nuclear Power systems

Albuquerque, New Mexico

J.2-16 January 1992

initial submission: 14 June 1991

final submission: 15 october 1991

Author to whom correspondence should be sent: Mr. David Buden 


\author{
David Buden \\ Idaho National Engineering Laboratory \\ P.O. BOx 1625 \\ Idaho Falis, ID $83415-1550$ \\ (208) $525-5626$
}

\begin{abstract}
Nuclear propulsion is necessary for succesgful Mars exploration to enhance cre's safety and reduce mission costs. Safety concerns are considered by some to be an impediment to the use of nuclear thermal rockeis for these missions. Therefore, an assessment was made of the various types of possible accident conditions that might occur and whether design or operational solutions exist. With the previoug work on the NERVA nuclear rocket, most of the isgues have been addressed in some detail. Thus, a large data base exist to use in an assessment. The assessment includes evaluating both ground, launch, space operations and disposal conditions. The conclusion is that design and operational solutions do exist for the safe use of nuclear thermal rockets and that both the environment and crews can be protected against harmful radiation. Further, it is concluded that the use of nuclear thermal propulsion will reduce the radiation and mission risks to the Mars crews.
\end{abstract}

\title{
INTRODUCTION
}

Nuclear thermal propulsion (NTP) is critical for successful human Mars exploration (Synthesis Group Report, 1991). The safety of the crew is greatly enhanced by shorter trip times. This has the affect of reducing the crew exposure to high levels of galactic radiation, reducing the time that solar flares will be a problem, lowering psychological stresses of long periods in confined environments and reducing the time the crew is subjected to possible equipment malfunctions. The nuclear thermal propulsion rocket engine has many fewer moving parts then chemical rockets which it replaces and should, therefore, be more rellable. There is no need for a chemical rocket oxidizer system. Launch windows for departing Earth and for returning from Mars are significantly wider. Also, there are more opportunities to go to Mars, providing schedule flexibility and reducing the need for potentially hazardous decisions to meet limited Mars opportunities. In addition, with nuclear thermal rockets two to three times better performance than chemical rockets, less or no assembly is needed in Earth orbit. This makes the spacecraft more reliable, less costly and easier to meet schedule. In fact, the mass in low Earth orbit will he one-third to one-half of a chemical rocket mission configuration.

\section{SAFETY QUESTIONS}

A series of questions relevant to the use of nuclear thermal rockets is postulated in order to evaluate accident conditions. These cover ground, launch and space operations (See Table 1) and were designed to encompass the full range of accident conditions that a NTP will need to address to demonstrate safe operations. No particular rocket engine configuration is used as a model. Thus, the assessment is to determine whether generic design solutions exist. F'or the postulated accident conditions, the primary safety requirements were determined, design options examined, and the experience base reviewed. The results are given in terms of top level summary discussions. Once a particular design is selected for either unmanned scientific or exploration missions or for crew missions to Mars, detailed design and operational solutions will be needed. The important element here is to have examined the key questions in significant depth to show that solutions exist.

The questions related to safe ground operations in Table 1 will now be addressed. 


\section{Ground Operations}

What must be done to safely ground test nuciear rockets?

What special precautions will be needed at the launch pad?

How will radloactive material contamination at the launch site be avoided in rocket launch pad accidents?

- Fires

- Explosions

How will ground testing be handied so that there are not significant additions to the nuclear waste problem?

Who approves the launch of vehicles with nuclear rockets on-board?

\section{Launch and Space Operations}

How safe is the crew from reactor radiaition?

How will inadvertent criticality be prevented for launch/ascent accidents?

If radioactive materials impact on land, what plans exist to clean up contaminated land areas?

If a reactor is started below a "Nuclear Safe Orbit" (NSO) or "Sufficient High Orbit" (SHO), how can reentry of a radioactive core be averted?

How is a "Nuclear Safe Orbit"determined?

Will nuclear engines relcase radioactive materials which contaminates near Earth space?

Will an operating nuclear rocket affect other satellites and experiments?

What are the plans for final disposal of nuclear engines in space?

Returning from Mars, how will a nuclear rocket be prevented from impacting the Earth?

\section{Safe Ground Testing of Nuclear Rockets}

Safety is the prime requirement in all testing and operational procedures. The established standards for radiation levels and radioactive releases levels must be met. Environmental Impact statements will be needed before testing facilities can be constructed.

To meet environmental safety standards, radioactive material removal scrubbers will probably be needed to remove fission gases from the engine hydrogen exhaust and to catch any radioactive material releases. The basic technology has been demonstrated during Nuclear Furnace-1 testing in 1972 (see Figure 1). In addition, a gcenario worst than what is considered the worst case credible scenario was intentionally tested in 1965 in Kiwi-TNT by building special rapid neutron control devices into the reactor. The result of the test showed that even in this extreme scenario that the reactor chemically exploded without significant nuclear contamination.

\section{Special Precautiong Needed At The Launch Pad}

The requirement is to maintain the radiation dose levels below established health standarda. Design options include not operating the reactor prior to launch (a zero power reactor test can be performed to verify the reactor physical. assembly is correct). Acceptance testing at the launch facility will be needed 


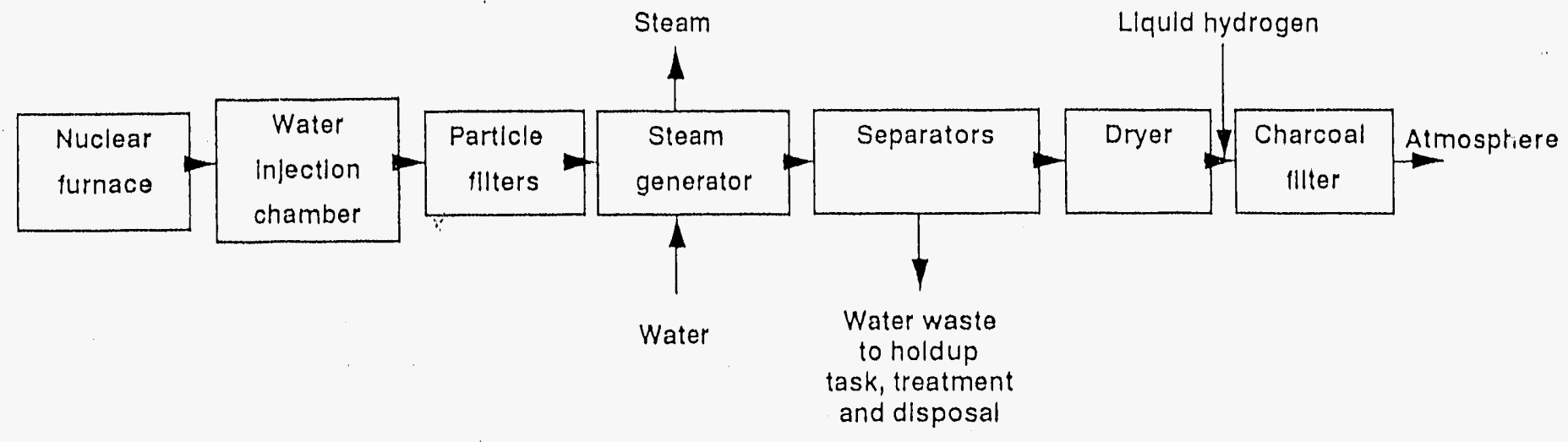

FIGURE 1. Nuclear Furnace Scrubber Concept

to ensure that all componentg are functional prior to mating with the launch vehicle. This could include cold flow testing; that is, teating where hydrogen is run through the engine for short periods of time to demonstrate that all valves and the turbopump are operational while maintaining the reactor shutdown.

The U.S. has launched one space reactor. This reactor, SNAP-10A, demonstrated the capability to launch a reactor without special radiation handling at the launch site. Further, nuclear fuels and reactors are transported around the country using well established containers and procedures. Sufficient design and operational experience exist to avoid transportation criticality accidents.

\section{Launch Site Contamination Accidents--Fires}

The primary requirement is to maintain the reactor subcritical without releases of hazardous radiation or radioactive materials during a fire. Design options relate to choice of materials and physical layout on the launch vehicle. For example, in case of an accident, it is more desirable to have the nuclear rocket in-line with chemical boosters rather then along side of them.

A series of propeliant fire testg were performed as part of a project called pyro to investigate the temperatures and duration of liquid propellant fires (Project Pyro, 1968). Theoretical data showed a peak temperature of $2900 \mathrm{~K}$ for hydrogen-oxygen fires. The experimental data measured $2500 \mathrm{~K}$. This is below the melting temperatures of the nuclear rocket fuel, so that melting is not a problem. An analysis of the structural materials also indicate that melting is insufficient to cause a critical mass.

Solid propellant test show that they burn at approximately $3000 \mathrm{~K}$, with some chucks burning for up to 10 minutes. Again, the fuel melting temperatures are above the fire temperature. Using evaluations of the Lincoln Laboratory Experimental satelites LES $8 / 9$ that used a Titan III launch vehicle, the probability of an accident is 2-3 in a hundred. In a given accident, the probability of propellant chunks being in close proximity to the reactor is between one in a thousand and one in a militon.

The conclusion is that the reactor can be designed not to melt or go critical in a launch pad fire. Detailed evaluations will be needed of particular nuclear thermal rocket and launch vehicle configurations.

\section{Launch Site Contamination Accidents--Explosions}

Here, the requirements are to prevent core compaction criticality and dispersal of radioactive materials. Design options are based on analysis from sp-100 where it was shown that the reactor would not go critical from the blast affects of launch vehicles. Similar design features can be built into nuclear rocket engines. Fragments may shear through the engine, but no fission fragment invensory exigts within the core at tuis time. Therefore, no signisicant 
radiological risk from an explosion is projected. A major safety analytical and experimental program has shown that radioisotope generatorg are safe to launch (Bennett, 1990); NTPs, with their geometry and non-radioactive materials at launch, should be even less risk at launch.

\section{Ground Nuclear Wagte}

The requirement is to minimize the amount of radioactive waste generated during the NTP program, egpecially long life waste. Detailed isgues will be addresged as part of a programmatic Environmental Impact statement. NTP characteristics tend to minimize nuclear waste because of the very short operating times, measured in hours. Reprocessing of the fuel and burning the actinides can minimize/eliminate nuclear waste. This was demonstrated when NERVA fuel was reprocessed and reused.

\section{Launch Approval}

It is required that a formal flight safety review be completed with the approval of the office of the President before nuclear power systems can be launched in the united States. This process, shown in.Figure 2 , requires an independent review by the Interagency Nuclear safety Review Panel that performs safety and risk evaluations (Sholtis and Nelson, 1990). The Panel provides the necessary independent risk evaluation that will be used by decision makerg who must weigh the benefits of the misgion against the potential risks. The agency

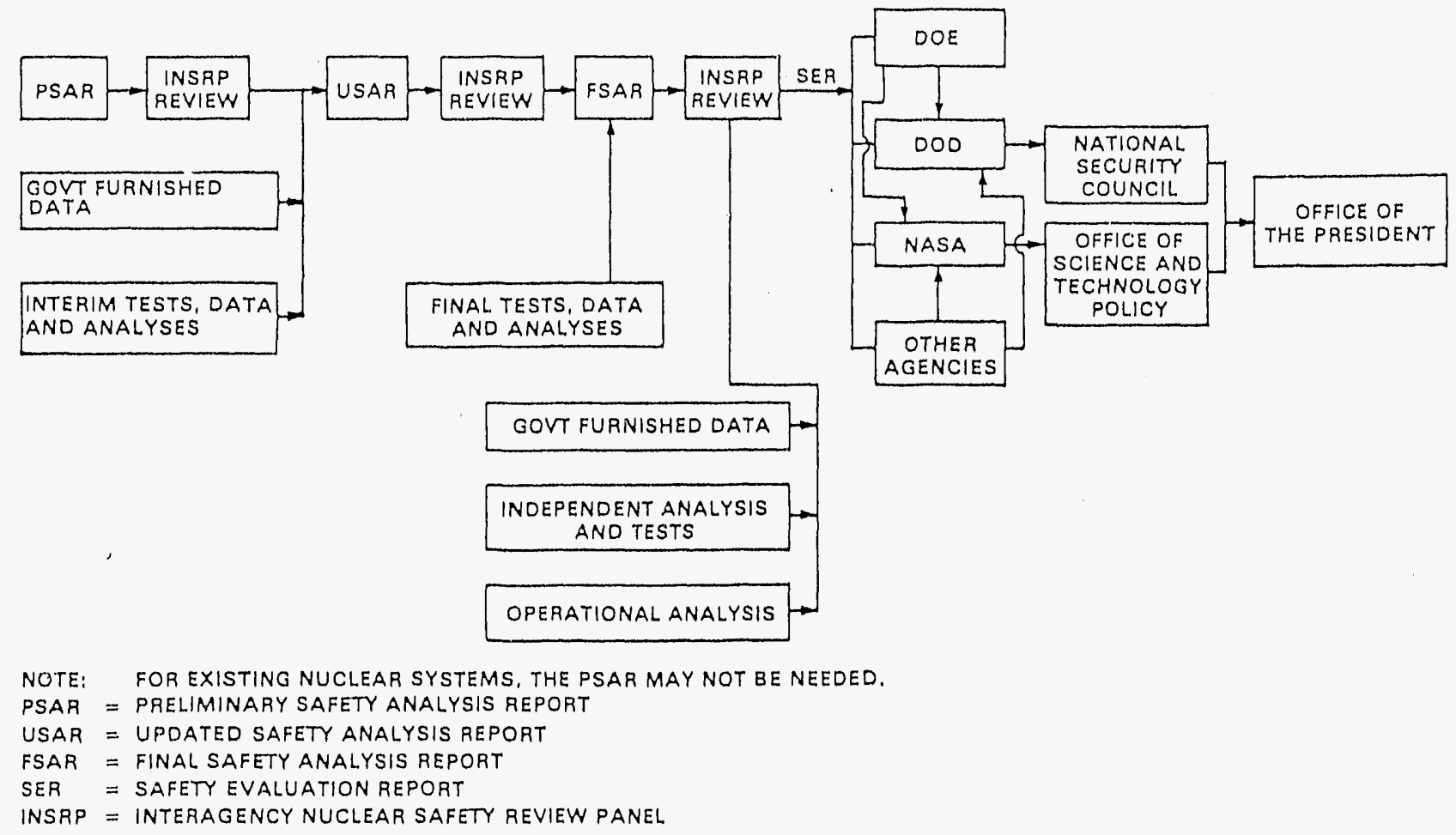

FIGURE 2. Flight Safety Review and Launch Approval process for Space Nuclear Power systems

wanting to fly a nuclear powered payload than requests permission for flight to the office of science and Technology (OSTP). OSTP reviews the request and makes the launch decision; however, the Executive office of the president makes the final decision if osTp feels that is appropriate. 
Turning now to launch and space operations, the questiong in Table 1 will be addressed.

Crew Safety From Reactor Radiation

NASA crew dose guidelines for astronauts is $50 \mathrm{rem} /$ year. Mars trips involve crew exposures to galactic cosmic radiation, Earth's radiation belts, solar radiation, and reactor radiation. Galactic cosmic radiation is continuous between 24 and $60 \mathrm{rem} /$ year. Solar flares are stochastic short duration events with potentially high doses ( $>120 \mathrm{rem}$; the crew can be protected by a storm shelter for the limited duration of the events. Earth's belt radiation is minimized by limiting the amount of time spent there. The radiation to the crew from a NTP reactor is reduced by spacecraft geometry, local reactor shielding, hydrogen tanks and spacecraft shielding to levels of about one rem. For a typical NTP Mars trip, see Table 2, the radiation exposure levelg for the crew is about 45 rem, of which the reactor contributes less than $3 \%$.

Criticality Prevention During Launch/ Ascent AcCidents

Requirements are for the system to remain subcritical for all credible launch/ascent accidents and to have no power operations until the system achieveg its intended orbit or flight path trajectory. Design options include a built-in redundant shutdown subsystems with sufficient design margins in each system to ensure shutdown in case of a failure within either subsystem. NERVA was designed, in addition to its control drums, with neutron absorption wires in the core through the nozzle to further protect against launch criticality. configurations can include in-core safety/shutdown rods or wires with locking devices and weisk links. Command destruction of the reactor can be provided to ensure that debris from an accident terminates in an ocean.

TABLE 2. Typical Mars Mission

(rem)

Galactic

34

Solar flares

7.7

(with storm shelter)

Earth radiation

belts $\quad 1.5$

Nuclear rocket $<1.1$

Mars (30 days) $\leq 1$

Total

45.3

\section{Plans To Clean up Contaminated I.and Areas}

If radioactive debris is deposited on land areas, it will be necessary to remove the material to designated storage sites. The approach here is mainly a preventative one. If an abort occurs near the beginning of the mission, the vehicle will likely land in the Atlantic ocean. Based on Titan and shuttle data, one failure in 57 flights of the solid rockets have occurred; however, no land impacts have occurred on other continents. The footprint from aborts later in the flight profile can be controlled by command destruct mechanisms to cause debris to fall into an ocean. Also, the reactor contains no radioactive fission products at launch. In the unlikely event of land debris impact, standard clean up organizations and mechanisms are in place such as the NEST Team (Nuclear Emergency Search Team).

operation Below "Nuclear Safe Orbit" or Sufficiently High Orbit"

Nuclear Safe orbit (NSO) or sufficiently High orbit (SHO) refers to the acceptable reactor space storage location after use. The latter term, sHo, is now preferred. It means an orbital lifetime long enough to allow for sufficient 
decay of the fission products to approximately the activity of the actinides before reentry occurs. One design option is to initiate operations above the sHo for a given misgion. However, for Mars missions and many others, $1 t$ will be highly desirable to start below sHo. For these missions, provision can be made for on-board or external boost systems. Nuclear thermal propulsion atages can be throttled to ensure that the thrust veotor is in an increasingly gafe direction before accelerating to full propulsion power. The stage can be slowly rotated to average the thrugt direction to safeguard againgt thrust nozzle misalignment failures. If fission gas retention is a problem at the higher temperatures, and correspondent higher rocket performance, the temperature can be reduced until the altitude is such that the fission gases are no longer a problem.

On-board devices have generally been used to boost low altitude gatelliteg to higher orbits. This approach has been demongtrated on the USSR RORSAT sateli1teg. However, these sometimes fail. An external capability is being evaluated under a project called SIREN (Search, Intercept, Recover, Expulsion Nuclear) for boosting radioactive materials to higher orbits (Lee, 1990 ).

\section{Determination of "Nuclear safe orbit"}

A NSO is a function of the geometry of the vehicle and operating history. Figure 3 shows the orbital decay time as a function of altitude in terms of mags, drag coefficient, and crosg sectional area. Typically, an orbital lifetime of 300 years has been used as the time for the radioactive materials from nuclear power plants to decay to safe radioactive levels. This corresponds to a orbital altitude above 400-500 nmi.

Near-Earth Space contamination

The requirements include no gignificant additiong of radioactive materials to the near Earth environment and protection of crews from expogures that exceed safety limits. During flight operations, insignificant amounts of figsion products are expected to be released. These should mostly be in the form of the fission gases. As part of the flight environmental impact statement, an assessment will need to establish acceptable fission gas release levels. If a sensitive environmental area is being traversed, power and temperature can be reduced to maintain releases to background levels.

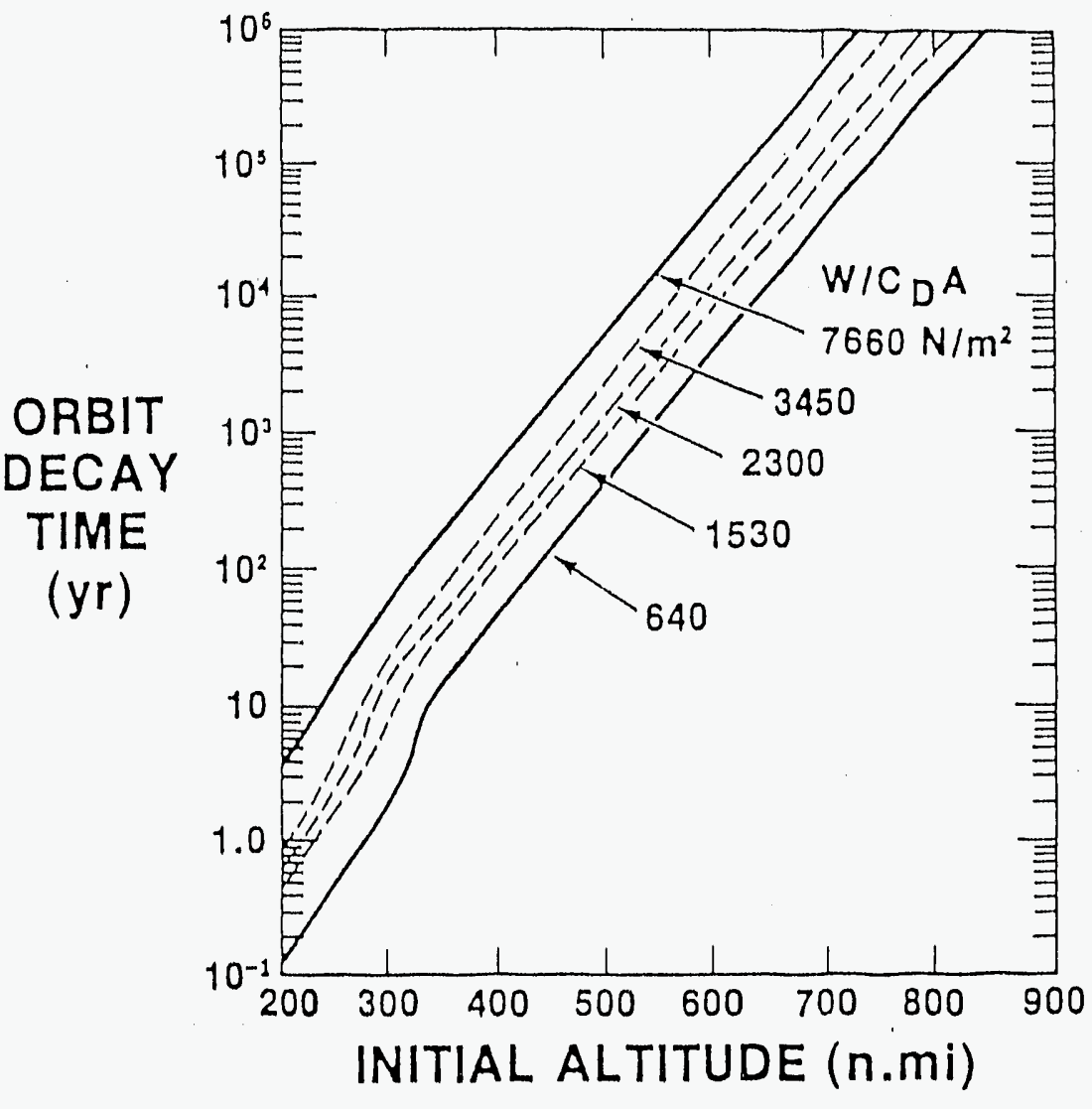

FIGURE 3. Orbital Decay Times 


\section{Affects on Other Satelliteg and Experiments}

It will be necessary to avoid/minimize affects on other satelites. This can be accomplished as part of particular mission planning. Operations should generally be well away from other satellites; the radiation level exposures at other Earth sateliltes is a function of distance, power level and duration. Just from the degire to avoid colilsions thege should be negligible; however, power can temporarily be reduced if necegsary in the vicinity of other satellites. During the limited operating time while leaving the vicinity of Earth (about 90 minutes), radiation sensitive sensors on other sateliltes will probably record the nuclear radiation from the reactor.

\section{Einal Digposal of Nuclear Enqines/Prevention of Nuclear Rocket Earth Impact}

Final disposal of nuclear engines must be such that there is negligible probability of intersecting or passing within the close proximity of Earth. From Mars, gince NTR reuse is not planned by the synthesis Group, it will be placed in a deep space orbit that will not intersect the Earth. The NTR stage can be ejected after the Mars burn or mid courge correction used to return the manned spacecraft to Earth; the NTR is not planned to be used in spacecraft Earth capture or achieving Earth orbit. From the Moon, if reuse is not planned, the NTR can easily be placed in a deep space disposal orbit. For a nuclear tug, it will eventualiy be disposed of either above a sufficiently High orbit or in deep space, not back to Earth.

\section{CONCLUSIONS}

Nuclear thermal propulsion can be designed to operate safely if safety standards are defined at the initiation of any nuclear thermal propulsion program and continuously monitored for compliance. Design and operational solutions to meet these standards have been addressed in previous programs, such as NERVA. The solutions depend on particular concepts and their intended migsiong. However, after reviewing a wide range of questions related to safety, there were no questions that did not appear to have practical design/operational solutions.

\section{Acknowledgments}

This work was performed under the sponsorship of the U.S. Department of Energy, Idaho Field office, DOE Contract \#DE-AC07-76IDO1570.

\section{References}

Bennett, G. I., "Safety status of space Radioisotope and Reactor power Sources," 25 th Intersociety Energy Conversion Engineering Conference, Reno, Nevada, August $1,1990$.

Lee, J., et al, "Technology Requirements for the Disposal of space Nuclear Power Sources and Implications for space Debris Management Strategies," AIAA/NASA/DOD Orbital Debris Conference: Technical Issued and Future Directions, paper No. AIAA 90-1368, Baltimore, Maryland, April 16-19, 1990.

Project Pyro, Liquid Propel lant Explosive Hazards, Final Report, AFPRO-TR-68-92, December 1968.

Sholtis, J., Joyce, J.P., and Nelson, R. C., "U.S. Flight Safety Review/Approval Process For Nuclear-powered Space Missions," Proceedings of the Seventh Symposium on Space Nuclear Power Systems, Albuquerque, New Mexico, January 1990, pp. 569-571.

Synthegis Group Report, America At The Threghold, America's Space Exploration Inltiative, avaliable from the superintendent of Documents, U.S. Government Printing office, Washington, D.C., 20402, June 1991. 
DATE

FILMED

5120192 


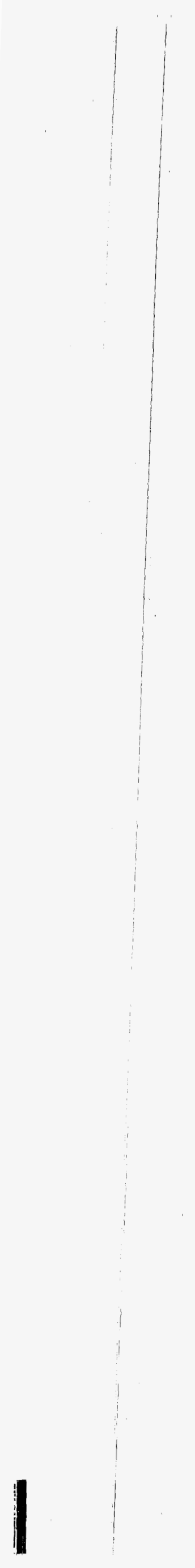

